\title{
Design optimization of a B-pillar for crashworthiness of vehicle side impact
}

\author{
A. E. Ikpe ${ }^{1^{*}}$, I. B. Owunna and P. Satope \\ Department of Mechanical Engineering, Coventry University, West Midlands, UK \\ *E-mail: ikpeaniekan@gmail.com \\ Phone: +2348125434634 or +447586821646
}

\begin{abstract}
In this study, Hypermesh and Catia V5 software were adopted for finite element analysis (FEA) of a vehicle B-pillar. The design objectives were to optimise the B-Pillar such that the maximum displacement, weight, and maximum stress value of B-Pillar is minimised without compromising its yield strength and impact resistant properties. This is significant for the improvement of a vehicle's crashworthiness and ensuring the safety of passenger(s) during road accidents. This study initially analysed a given B-pillar design after being subjected to an even force of $140 \mathrm{kN}$. The result produced von Mises stress of $1646 \mathrm{MPa}$ and deflection of $5.9 \mathrm{~mm}$. To ensure that EuroCAP directives were met, the BPillar was reinforced by adding extra steel plates to its inner surface and applying seam welding to ascertain their fusion and analysed using the same force of $140 \mathrm{kN}$. Analysis of the reinforced B-Pillar design produced maximum von Mises stress of $673 \mathrm{MPa}$ with a maximum displacement value of $2.39 \mathrm{~mm}$. The optimised B-Pillar design was reinforced with $1.7 \mathrm{~kg}$ steel plate with the overall mass of the B-Pillar amounting to $4.2 \mathrm{~kg}$ of the total design compared to the original B-Pillar which had a total mass of $6 \mathrm{~kg}$. The optimised BPillar possessed less weight beside capable of resisting a force of $140 \mathrm{kN}$ with von Mises stress and displacement rate lower than the original B-Pillar. Thus, this indicates improvement in the tensile strength, stiffness, and impact resistant behaviour against collision forces by acting sideward on vehicles during road accidents. This can save such vehicles and passengers from severe damage that may result in loss of lives and properties. Hence, B-Pillar must be designed following the existing standards and tested before installation on vehicles to avoid unforeseen catastrophes.
\end{abstract}

Keywords: B-pillar, design; crashworthiness; side impact; vehicle, safety.

\section{INTRODUCTION}

Structural optimisation is very important in engineering designs. It is an important tool used to remove unnecessary features and improve the function of a component or system. The main objective of this study is to analyse the structural capacity of a B-Pillar design used in automobiles. The result will be an optimised model that meets EuroCAP directives. The B-pillar is an essential load-carrying element in any automobile framework. It functions as a primary supporting structure for the roof. It is characterised by a thin-walled, seam-welded, closed-sectioned structure made from high strength steels [1-3]. B-pillar is the most forward pillar on each side of a vehicle that is in whole or part, rearward of a transverse vertical plane passing through the seating reference point of the driver's seat[4]. B-Pillar is the pillar presents on both sides of a given vehicle between the rear and front doors. The B-Pillar mounted on a vehicle for latching of the front doors 
and installing hinges for the rear doors is a steel structure welded firmly on one end to the rocker panel and floor pan at the bottom of a vehicle while the other to the roof rail for rigidity and support to the roof panel [5-7]. Due to the number of standard requirements to satisfy optimum performance against crushing of the roof, B-pillar has become an important part of car designs. Therefore, it has become an important aspect of the engineering design process for modern day cars.

Its importance to occupant safety makes the B-pillar an essential component in the crashworthiness of vehicle side impact. However, this necessitates the complex nature of a B-pillar design with respect to high impact resistance against unforeseen side collision of vehicles. The position of the B-pillar in a vehicle makes it very important in the provision of high impact resistance and safety to vehicle occupants in crash events that involve side impact [8]. The maximum stress exhibited by high impact structural members (such as the B-Pillar) after deformation is of great importance, as it helps to predict whether the material has exceeded its yield limit or not. This is usually achieved by conducting a pole side impact test (known as Advanced Euro Mobile Deformable Barrier-AEMDB) or virtual test [6,9]. However, strengthening or reinforcing structural members is more advantageous than substituting with new or redesigned members as sufficient resistance against external load can be achieved [10]. Figure 1 shows a typical car model with B-Pillar installed on both sides.

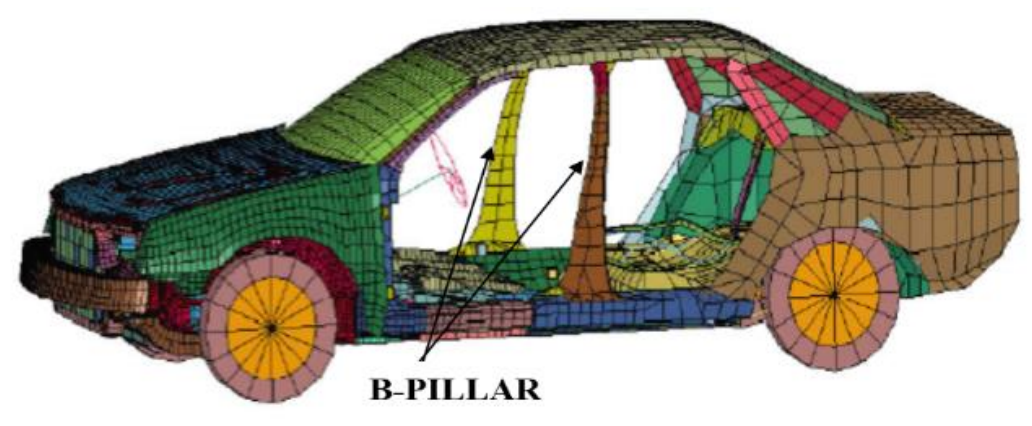

Figure 1. Typical car frame showing B-pillar location [11].

Accidents involving side impact may result in severe injuries to the vehicle occupants, particularly when drivers exceed the required speed limit in populated areas or highways. Most side impacts can be classified into two types; car-to-broad-object and car-to-narrow-object. B-Pillars are often designed to withstand side impact forces and still remain elastic after the impact has occurred [12, 13]. Examples of narrow objects involved in side impacts are trees, poles, lamp posts, and barrier tubes [14]. Road accident in recent times has become a global problem that claims millions of lives of road users annually, where an average of 3,500 people sustain severe damages and loss of lives daily [15]. Existing studies have shown that one out of five road accidents involves side collision which accounts for $75 \%$ of injuries sustained by vehicle occupant [16]. This is often caused by ignorance on the path of manufactures to pay specific attention to existing standards on the crash worthiness of vehicle side impact which majorly depends on design integrity of the B-Pillar. This problem necessitated the optimisation (by reinforcement) of a B-Pillar such that its performance is not compromised while the stiffness, strength, and impact resistance of the pillar are increased with no further increase to the B-Pillar overall weight which may be disadvantageous in terms of the vehicle fuel consumption rate. Crash impact analysis usually unravels the effects of linear static forces acting on vehicular structures in terms of energy absorption and deformation upon low and high- 
velocity impacts [17]. In certain case, reinforcing the B-Pillar becomes necessary for effective attenuation of impact forces during crash scenarios. This is in accordance with the federal motor vehicle safety standards (FMVSS) and regulations (standard number 214) to protect vehicle occupants from severe harm during road accidents [13]. This standard specifies performance requirements for protection of occupants in impact crashes.

The purpose of this standard is to reduce the risk of serious and fatal injury to occupants of passenger cars, multipurpose passenger vehicles, trucks, and buses. The analysis in this study was carried out from the understanding of the worst-case scenario in which the B-Pillar after side impact is subjected to bending, buckling, and possible breakage depending on the severity of the impact. A force of $140 \mathrm{kN}$ evenly distributed across the B-Pillar was considered. The crash impact can be analysed using HyperWorks, FEA software or software add-in software for FEA in CATIA as well as ANSYS. The analysis was done using the best mesh size in order to increase the accuracy of the results obtained. From this analysis, a suitable understanding of the optimised design was then deduced indicating which areas are the most important for the structure and which parts can be simplified, allowing for several design recommendations to be made.

\section{METHODS AND MATERIALS}

Linear static analysis of the B-pillar design was initially carried out on a B-Pillar of $1.4 \mathrm{~mm}$ thickness using HYPERMESH and Catia V5. The same B-Pillar was reinforced with a thin plate of $2 \mathrm{~mm}$ to follow the ' $\mathrm{C}$ ' section similar to the B-pillar inner surface and reanalysed. Identical loading and contact conditions were applied with deviations in the boundary conditions. The B-pillar design was constrained to provide a more rigid boundary condition. Instead of constraining the top and bottom edges, the extended faces were clamped to restrict movement in all six degrees of freedom and seam welded to the B-pillar inner cavity. The following steps were adopted to achieve the objectives of this study. The B-pillar was meshed using different sized elements and the best mesh was selected. Maximum displacement and Von Mises stress values were noted for each mesh size. Graphs of maximum displacement vs mesh size and Von Mises stress against mesh size were generated. 2-D and 3D mesh sizes were used to represent the elements. The distributed load of $140 \mathrm{KN}$ was applied on the face of the B-pillar as instructed in Ydirection of vehicle coordinating system. Seam weld joints were created between edges of reinforcement and the inner surface of redesigned B-pillar. Surface contact conditions were defined between the inner surface of B-pillar and outer surface reinforcement touching the B-pillar.A factor of safety of 1.25 was considered for designing. Material thickness of $2 \mathrm{~mm}$ was assigned to reinforcement and $1.4 \mathrm{~mm}$ thickness was assigned to B-pillar.

\section{B-PILLAR DESIGN ANALYSIS}

The B-pillar was analysed by applying a force of $140 \mathrm{kN}$ evenly across its outer surface. The loaded structure was constrained on both the lower and upper surface. However, the constraints may not fully represent the exact life scenarios as the surfaces welded to the car body is an extended surface from the top and bottom. The scenario was assumed because of the close proximities of the stress values from the analysis of the real-life scenario and the assumed test setup. Nevertheless, this may have decreased the precision of the analysis on the B-Pillar by $15 \%$ whopping or less. These constraints positioned the 
model in all the six degrees of freedom. Initial FEA of the original B-Pillar and assumed test setup are presented in Figure 2.

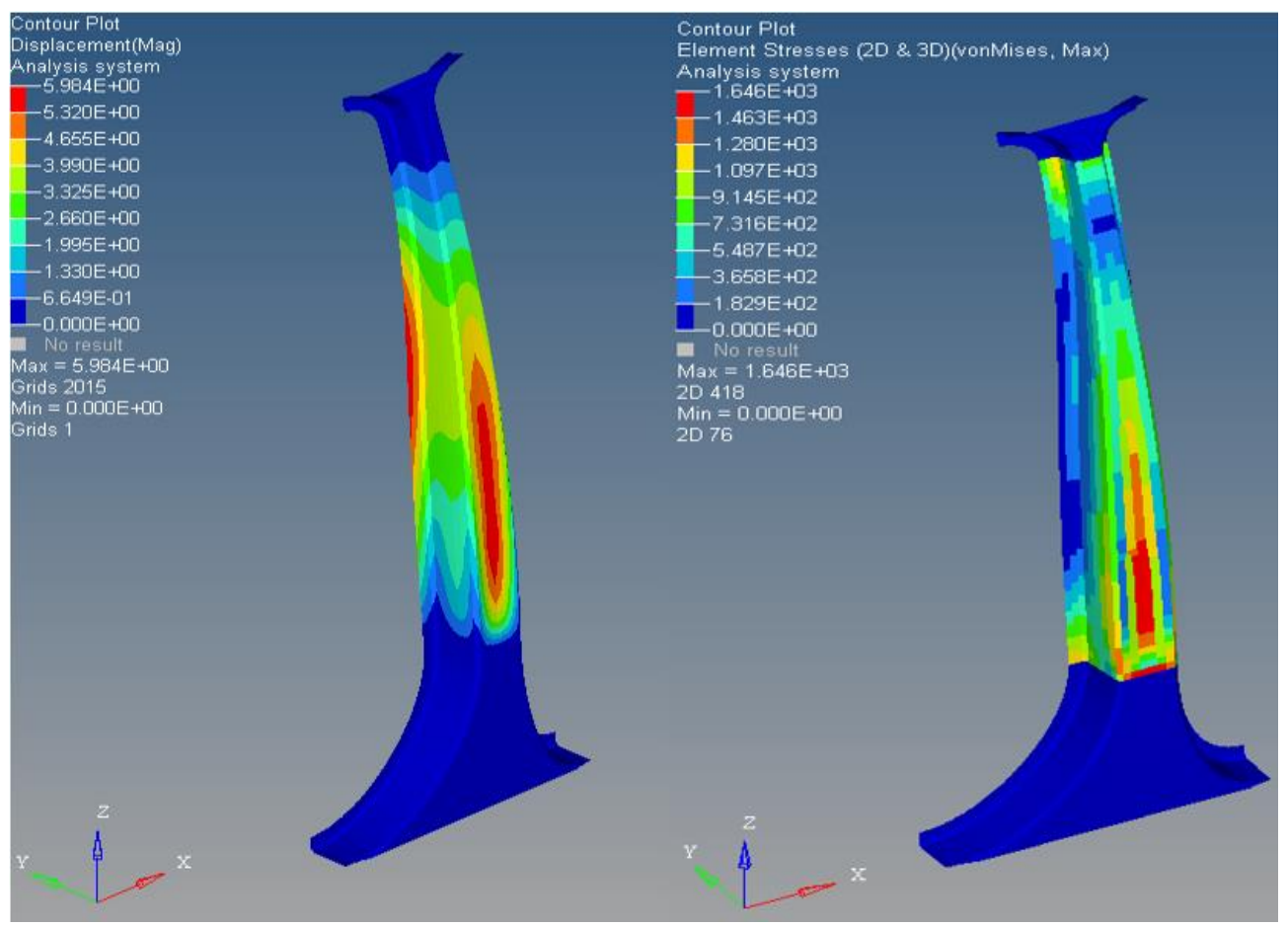

Figure 2. Finite element analysis of the original model.

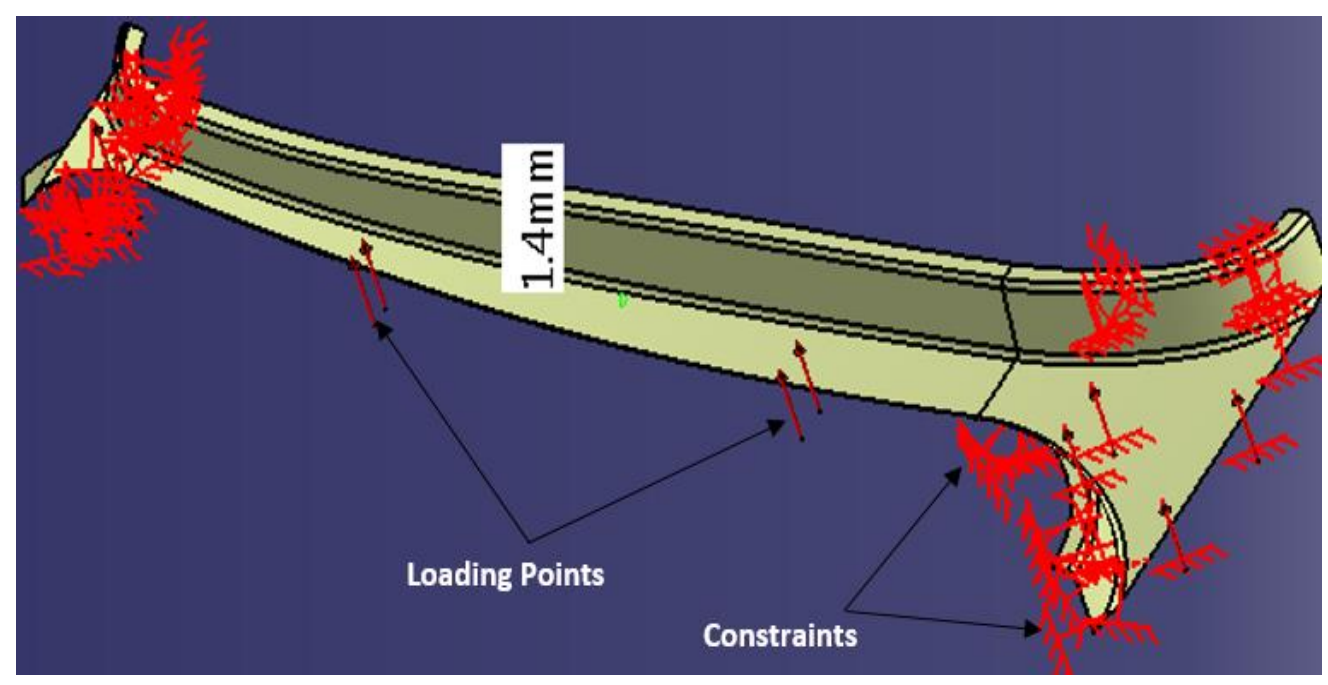

Figure 3. B-pillar load case.

The analysis was carried out with HYPERMESH, and H3D plots of displacement, as well as von Mises stress, were produced. The maximum displacement was $5.9 \mathrm{~mm}$ while the maximum stress was $1646 \mathrm{MPa}$ as shown in Figure 2. The stress plot in CATIA FEA analyser produced the maximum stress that occurred along the edges of the constraints. However, the HYPERMESH solver showed stress concentrations on the edges as well as the centre of the B-Pillar. In actual vehicles, the B-pillar displacements are higher in real life than that obtainable in the assumed load case. The relationship 
between the stress and displacement is direct, as such lower stress will produce a lower displacement. The assumed load case is shown in Figure 3.

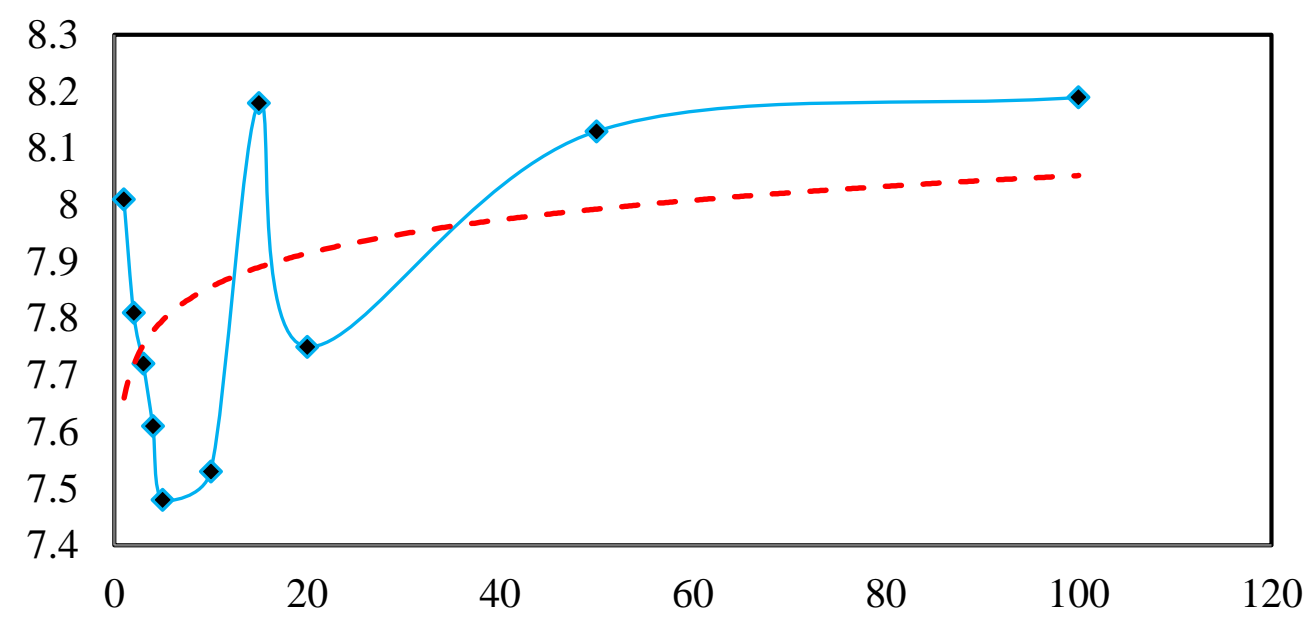

Figure 4. Variation of displacement against mesh size.

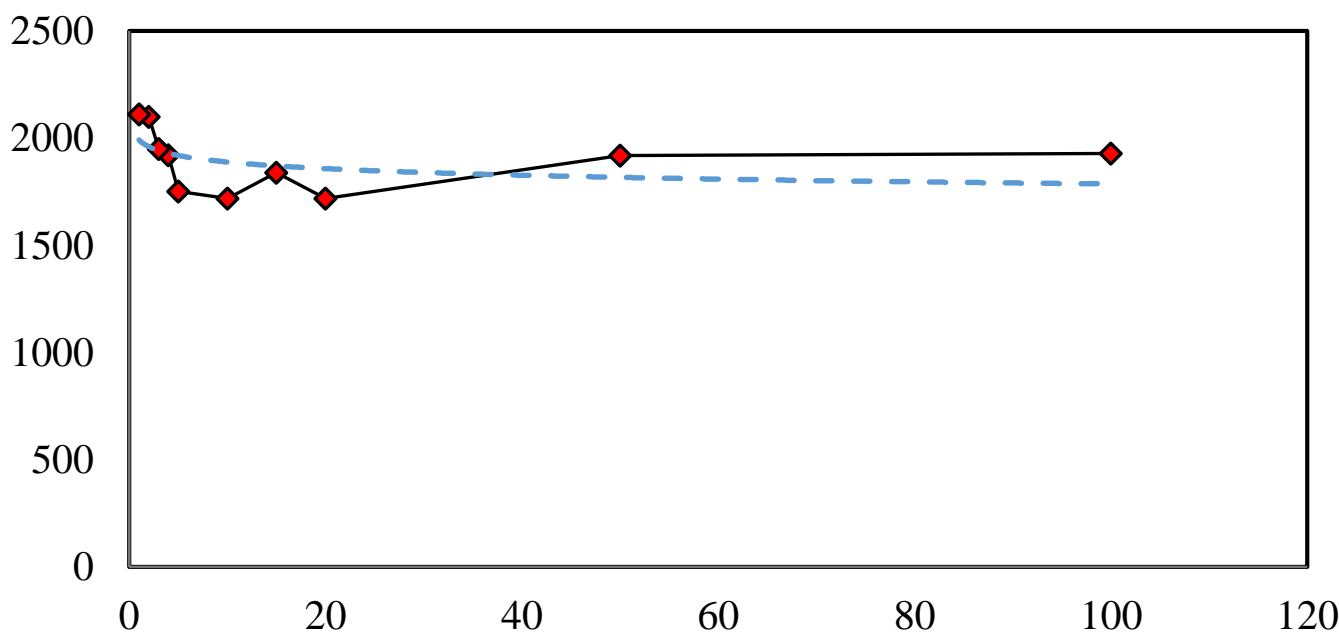

Figure 5. Variation of von Mises stress against mesh size.

The computer programmes used for FEA apply numerical methods in the estimation of the various mechanical properties of engineering designs that can withstand a set of loads [18-21]. Engineers are able to substitute physical testing with FEA solutions which have a direct effect on time and economics of engineering analysis, design, and design standardisations. Companies now perform cheaper, faster, and sophisticated researches as well as design effortlessly. Linear FEA has helped to solve real-life problems for many years while the expansions in engineering practices ensure that more sophisticated tools like non-linear systems are developed [22]. Linear systems do not account for plastic deformation in engineering systems, although it is possible in nonlinear systems. Non-Linear systems can often be used for material testing where the behaviour all the way to failure is to be examined. A mesh was formed by a system of nodes $[23,24]$. The FEA solvers utilise a system of nodes in generating meshes on any model that would be analysed. The number of nodes dividing a model defines the type of generated mesh. The meshes were expected to retain the properties of the model that 
affected the reaction of the model to a system of forces. There are two categories of meshes namely, 2D and 3D meshes, which each has various types. 3D meshes apply 3D properties and shapes on the model and produce relatively accurate results but the major disadvantage of this type of mesh is high computation time. 2D meshes are easier to create compared to 3D meshes as it applies 2D elements/shapes in generating the model to enhance the results and computation time. It is often very advisable to apply the same size of the mesh in generating a model to reduce stress concentrations. Appropriate mesh size will ensure accurate result at a relatively smaller computing time. Mesh convergence study applied in this analysis helped to produce the curves shown in Figures 4 and 5. The curves suggest a mesh of $10 \mathrm{~mm}$ size which will produce accurate results for stress and displacement.

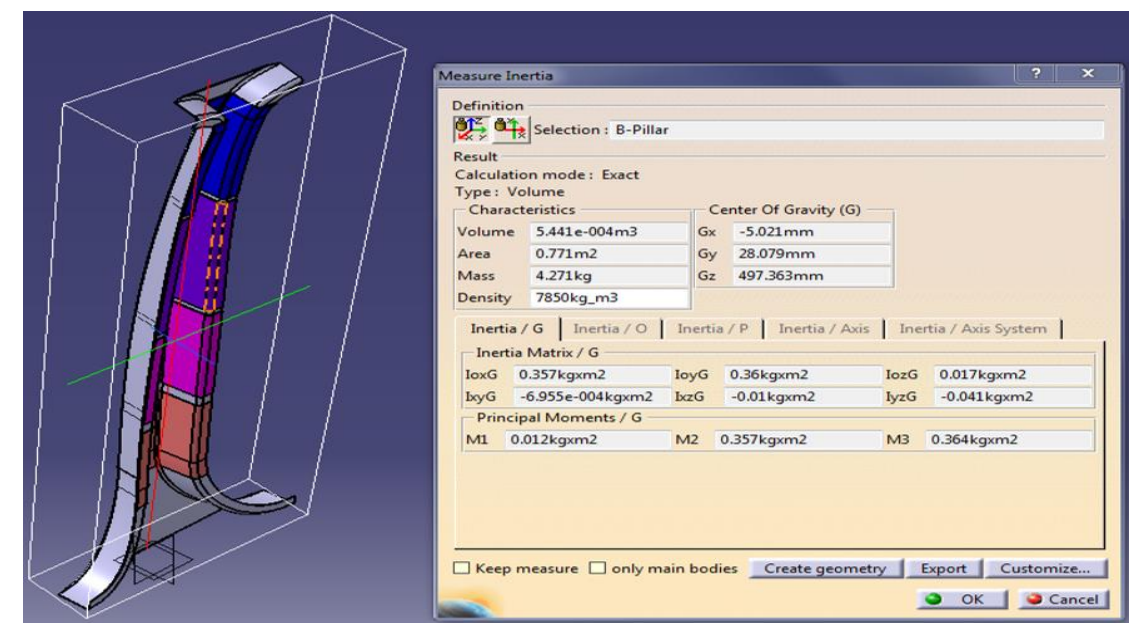

(a) Total mass of B-Pillar with reinforcement

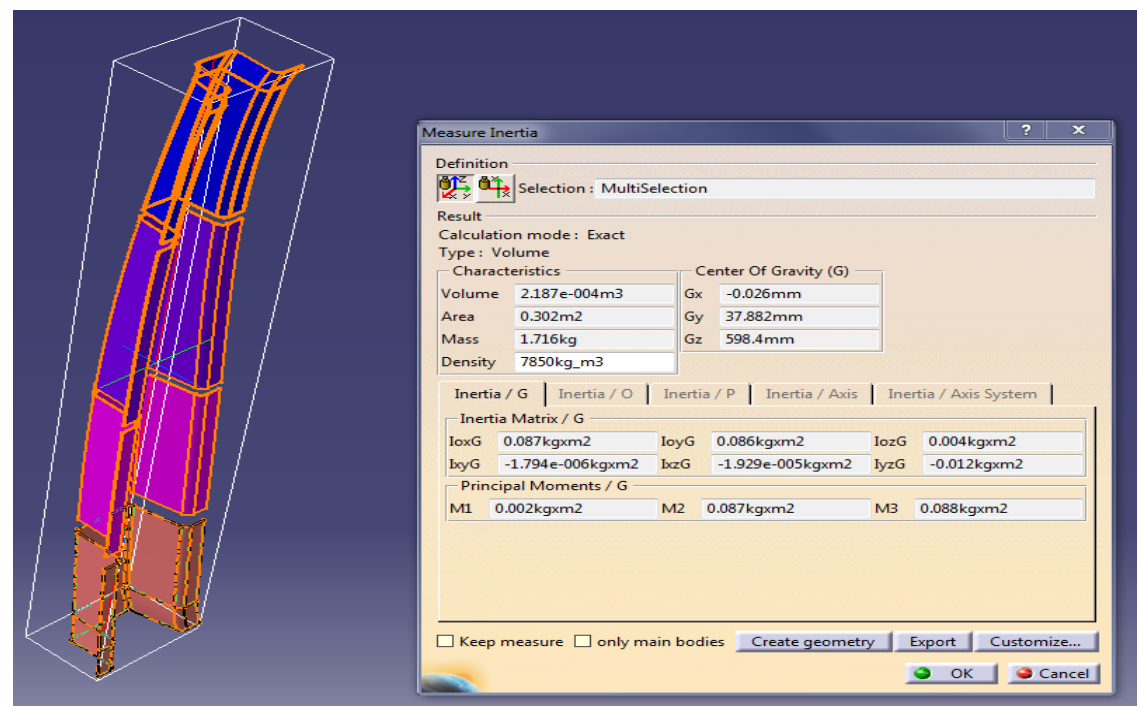

(b) Total mass of the reinforcement

Figure 6. Measured inertia showing for the optimised design.

\section{Design Considerations}

This relates to the critical or highly required functional elements of a component being evaluated. Oftentimes, the efficiency of the component depends upon these elements 
which must be defined appropriately to avoid unforeseen failure events, downtime, and damages in terms of loss of lives and properties while giving the guarantee of safe operation. In this case, crashworthiness of the B-Pillar is one of the functional elements that depend highly on the material properties such as the modulus of elasticity, tensile strength, and yield strength in order to offer the required resistance against the effects of severe forces acting on the B-Pillar.

\section{Moment of Inertia}

The moment of inertia was used to measure an object's resistance to variations in its rotation. It depends majorly on the axis of reference where the centroid passes. The second moment of area and acting forces determine the deflection of any beam under a system of forces. The analysis for a moment of inertia of the reinforced B-pillar is shown in Figure 6. For the B-Pillar reinforcement, the bending moment is often reduced or the moment of the area increased.

\section{Euro NCAP and Directive Standards}

The requirements for the European New Car Assessment Programme (Euro NCAP) standards stated that vehicles must pass safety requirement prior to being marketed. The safety requirements, as well as techniques for such tests, are set out by $500 \mathrm{X} 1500 \mathrm{~mm}$ impact requirements at a speed of $50 \mathrm{~km} / \mathrm{h}$ on the side of a car where the B-Pillar is located. It is specified by Euro NCAP that the static displacement of the car must be $340 \pm 20 \mathrm{~mm}$, speed of $50 \mathrm{~km} / \mathrm{h}$, dynamic peak displacement of $346 \pm 20 \mathrm{~mm}$, and total weight of $1300 \pm$ $20 \mathrm{~kg}$ with total energy absorption of $61 \pm 5 \mathrm{~kJ}$ for the movable barrier [8, 12]. In this report, the $140 \mathrm{kN}$ force was used to analyse the B-Pillar for crashworthiness. In the B-Pillar design, the material used for the outer surface and reinforcement differed in strength. The design parameters for the B-pillar analysis conducted in this report are given in Table 1, while the material specification for the B-pillar design is shown in Table 2. Other than the side impact, B-Pillars are designed to resist roof crushing in rollover accidents. The various parts of the B-Pillar must allow seam welding. This limited the first design idea in this paper.

Table 1. B-pillar design dimensions.

\begin{tabular}{lr}
\hline Parameters & Values \\
\hline Height & $1000 \mathrm{~mm}$ \\
Width A & $\leq 400 \mathrm{~mm}$ \\
Width E & $\leq 180$ \\
Rake & $120 \mathrm{~mm}$ \\
Depth A & $\leq 70 \mathrm{~mm}$ \\
Depth E & $\leq 50 \mathrm{~mm}$ \\
Angle Front & $\geq 90$ \\
Angle Rear & $\geq 90$ \\
Seam & $\geq 20 \mathrm{~mm}$ \\
Fillet Outer & $\geq \mathrm{R} \mathrm{5.0mm}$ \\
Fillet Inner & $\geq \mathrm{R} 2.5 \mathrm{~mm}$ \\
\hline
\end{tabular}

\section{Crashworthiness}

Crashworthiness can be defined as the ability of a vehicle and its structural components to protect its occupants in the event of a crash. The nature of the crash and operational category 
or type of the vehicle plays a very crucial role in determining the crashworthiness of the vehicle $[8,13]$. Before actual vehicle prototypes are subjected to crash tests, the vehicle design and design of all its structural components are analysed through computers and finite element methods. The results of this analysis serves as a guide for designing all other components. B-pillar in any vehicle is primarily subjected to side impacts and roof crush test in the case of vehicle rollover and any car that fails the test is not qualified to be sold. To ascertain the crashworthiness of a vehicle side impact, AE-MDB recommended the following side impact test requirements:

i. Movable barrier total energy absorption: $61 \pm 5 \mathrm{~kJ}$

ii. Total speed: $50 \mathrm{~km} / \mathrm{h}$

iii. Dynamic peak displacement: $346 \pm 20 \mathrm{~mm}$

iv. Total weight: $1300 \pm 20 \mathrm{~kg}$

v. Static displacement of car: $340 \pm 20 \mathrm{~mm}$

The B-pillars must be designed considering these aforementioned standard requirements.

Table 2. Material specification for he B-pillar design.

\begin{tabular}{cccccccc}
\hline Component & $\begin{array}{c}\text { Maximum } \\
\text { Thickness } \\
(\mathrm{mm})\end{array}$ & Material & $\begin{array}{c}\text { Density } \\
\left(\mathrm{Kg} / \mathrm{m}^{3}\right)\end{array}$ & $\begin{array}{c}\text { Young's } \\
\text { Modulus } \\
(\mathrm{MPa})\end{array}$ & $\begin{array}{c}\text { Yield } \\
\text { Strength } \\
(\mathrm{MPa})\end{array}$ & $\begin{array}{c}\text { Tensile } \\
\text { Strength } \\
(\mathrm{MPa})\end{array}$ & $\begin{array}{c}\text { Poison's } \\
\text { Ratio }\end{array}$ \\
\hline B-Pillar & 1.4 & $\begin{array}{c}\text { CP Steel } \\
800 / 1000 \\
\text { Reinforcement }\end{array}$ & 7850 & 210000.003 & 800 & 1000 & 0.3 \\
& 2.0 & $\begin{array}{c}\text { High } \\
\text { Alloy } \\
\text { Steel }\end{array}$ & 7850 & 210000.003 & 1500 & 1700 & 0.3 \\
\hline
\end{tabular}

\section{Von Mises Stress and Factor of Safety}

Von Mises stress is the design criterion used in ductile materials to analyse failure. It helps verify how a design performs under a system of forces. It predicts whether failure will set in or not. If at any point in the model, von Mises stress induced in a material is higher than the yield strength of the material in the design, failure occurs. Details of the material used in the design of the B-Pillar are shown in Table 2. The factor of safety (FS) for this report may be determined based on the material property or the load safety factor. This can be determined as shown in Eq. (1);

$$
\text { Factor of safety }(F S)=\frac{\text { Yield strength }}{\text { Allowable or design Stress }}
$$

From Equation (1), the allowable or design stress can be expressed as:

$$
\text { Allowable or design Stress }=\frac{\text { Yield strength }}{\text { Factor of safety }(\mathrm{FS})}
$$

The B-pillar can be modelled as point load with the maximum deflection given as:

$$
\delta_{\max }=\frac{P l^{3}}{48 E I}
$$

where $\mathrm{E}=$ Young's modulus, $\mathrm{P}=$ load, $I=$ second moment of area, and $l=$ length of the Bpillar.

Applying Eq. (3) to the theoretical calculation gave a maximum deflection of $4.04 \mathrm{~m}$, approximately equal to $4040 \mathrm{~mm}$. However, the value was too high and cannot be used in the design. For uniformly distributed load which is usually the case in collisions involving side impact of a vehicle, the deflection can be expressed as Eq. (4). 
Therefore,

$$
\delta_{\max }=\frac{5 w l^{4}}{384 E I}
$$

where $w=$ uniformly distributed load.

$$
\delta_{\max }=\frac{5 P l^{3}}{384 E I}
$$

Applying Eq. (5) in the theoretical calculation gave a maximum deflection of $52.6 \mathrm{~mm}$. Making $I$ the subject of the formula, the maximum deflection value was less than $40 \mathrm{~mm}$ as shown in Eq. (6):

$$
I=\frac{5 P l^{3}}{384 E \delta}
$$

Applying Eq. (6) in the theoretical calculation gave a deflection value of $2.17 \times 10^{-}$ ${ }^{7} \mathrm{~m}^{4}$. From the deflection standpoint, $I$ should be greater than $2.17 \times 10^{-7} \mathrm{~m}^{4}$. To determine the allowable stress, the equation used is given as:

where $y=$ Deflection, $\sigma=$ stress

$$
\sigma=\frac{y P l^{2}}{8 I}
$$

Applying Eq. (7) gave the stress value of $1590.91 \mathrm{MPa}$. Making $I$ the subject of the formula, stress value less than 1590.91 MPa can be obtained as shown in Eq. (8).

$$
I=\frac{y P l^{2}}{8 \sigma}
$$

The design load, however, defines the working load that any design is expected to withstand in its full operation. The factor of safety is the ratio of failure load to the design load. It can as well be the ratio of yield stress to the allowable/design stress. To estimate the possible factor of safety for materials, the ratio of tensile strength to yield strength was taken. For both materials in Table 2, the ratio of tensile strength to yield strength gave 1.25 and 1.13. To design the B-Pillar, the ratio of yield strength to tensile strength for the B-Pillar outer material was used. Applying the factor of safety to the yield strength of $800 \mathrm{MPa}$ reduced the allowable stress to $640 \mathrm{MPa}$. The design was therefore done to ensure the von Mises stress within $640 \mathrm{MPa}$ range.

\section{Elastic Region and Ultimate Tensile Strength}

The ultimate load defines the value of load at which a system fails and this depends upon the ultimate tensile strength of the material [25] given as in Eq. (9).

$$
\sigma_{u}=\frac{P}{A_{o}}
$$

where $F=$ Applied load at the point of failure and $A_{o}=$ Original cross sectional area of the B-pillar.

This may be considered in cases where the B-pillar is in tension due to the crash impact on the vehicle. Under this condition, the load $(P)$ is considered as stress by calculation and $\mathrm{A}_{o}$ which is the original area of the B-pillar is given as in Eq. (10).

where, $d_{o}=$ Original diameter of the beam

$$
\mathrm{Ao}=\frac{1}{4} \pi d_{o}^{2}
$$

The elastic limit or yield point is the point at which a material deforms plastically under a system of forces. This point is defined by the yield strength of the material. It is the maximum stress within a system that causes the material to undergo plastic deformation. 
The deformation of a material takes an elastic form before it reaches its yield point. In this form the body returns to its initial condition when the forces are relaxed [26]. Plastic deformation which takes place when a material exceeds its yield point defines a permanent or non-reversible deformation. From an energy absorption point of view, crashworthiness of a vehicular structure like the B-Pillar may not be omitted in designing a vehicle since it is essential to reduce the number of casualties resulting from an impact event, enhancing crash energy absorption and minimising deformation of the vehicle structure in post-collision [27, 28]. Oftentimes, specific absorption energy of a material can be used to estimate the specific amount of energy can be absorbed by the B-Pillar when acted upon by external force and this may be given by Eq. (11).

$$
E_{S}=\frac{E}{\rho \delta A_{m a t}}=\frac{\int_{0}^{\delta} F d x}{\rho \delta A_{m a t}}
$$

where $E_{s}$ is the energy absorbed by the B-Pillar, $\mathrm{A}$ is the cross-sectional of the B-Pillar, F is the applied force and $d x$ is the thickness of the B-Pillar.

In the crash events where the B-Pillar is extremely damaged and occupants sustain head injured [1], the head injury criterion (HIC) is calculated using Eq. (12).

$$
\mathrm{HIC}=\left[\frac{1}{t_{2}-t_{1}} \int_{t_{1}}^{t_{2}} a(t) d t\right]^{2.5}\left(t_{2}-t_{1}\right)
$$

For the B-pillar, stresses do not act in the same direction. As a result of that, yield strength cannot be used as the determining factor as it is a unidirectional property although many theories have been proposed to simplify the case. The von Mises stress helps in predicting the yielding of a material when subjected to complex loading conditions. Applying the von Mises theory, the parts that have equal distortion energy will experience the same stress. The yielding criteria for von Mises stress can be expressed by the yield stress relationship in Eq. (13).

$$
\sqrt{\frac{1}{2}\left(\sigma_{x}-\sigma_{y}\right)^{2}+\frac{1}{2}\left(\sigma_{x}-\sigma_{z}\right)^{2}+\frac{1}{2}\left(\sigma_{y}-\sigma_{z}\right)^{2}+3\left(\tau_{x y}+\tau_{x z}+\tau_{y z}\right)^{2}}=\sigma_{Y}
$$

where, $\sigma_{\mathrm{x}}, \sigma_{\mathrm{y}}, \sigma_{\mathrm{z}}=$ principal stresses in the corresponding direction, $\tau_{\mathrm{xy}}, \tau_{\mathrm{xz}}, \tau_{\mathrm{yz}}=$ shear stresses in corresponding planes, and $\sigma_{\mathrm{Y}}=$ yield stress.

Instead of stress and strain, von Mises includes the principal stresses on its axis. Von Mises is denoted in Eq. (14) [29].

$$
\left.\sigma_{V M}=\sqrt{\frac{1}{2}\left(\left(\sigma_{x}-\sigma_{y}\right)^{2}+\left(\sigma_{x}-\sigma_{z}\right)^{2}+\left(\sigma_{y}-\sigma_{z}\right)^{2}\right.}\right)
$$

\section{Existing B-Pillar Designs}

Considering the existing B-Pillar designs shown in Figures 7-9, a number of salient points can be studied to aid the design in this case. The cogent suggestions from the previous designs of B-pillars include:

i. The ends of the B-pillar should be thicker than the middle sections.

ii. Smooth edges rather than sharp counterparts help limit stress concentrations.

iii. The highest factor of safety from considering all materials involved in the design should be used in the computation. 


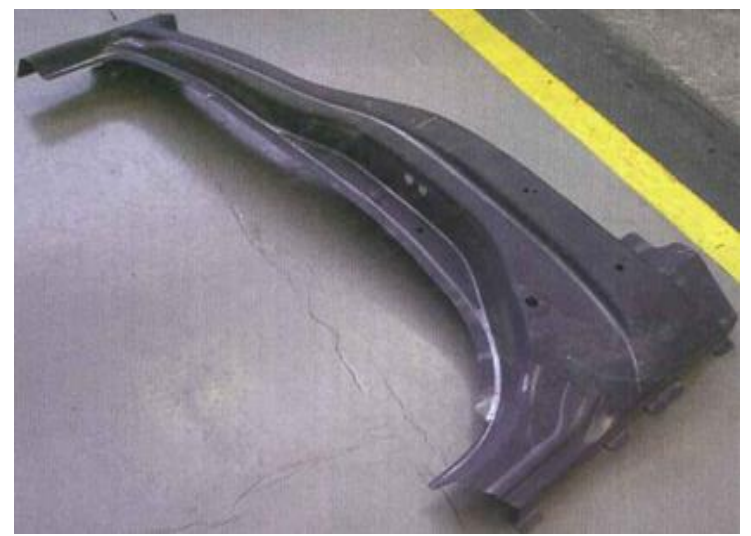

Figure 7. Real Life example of Car B-Pillar [30].

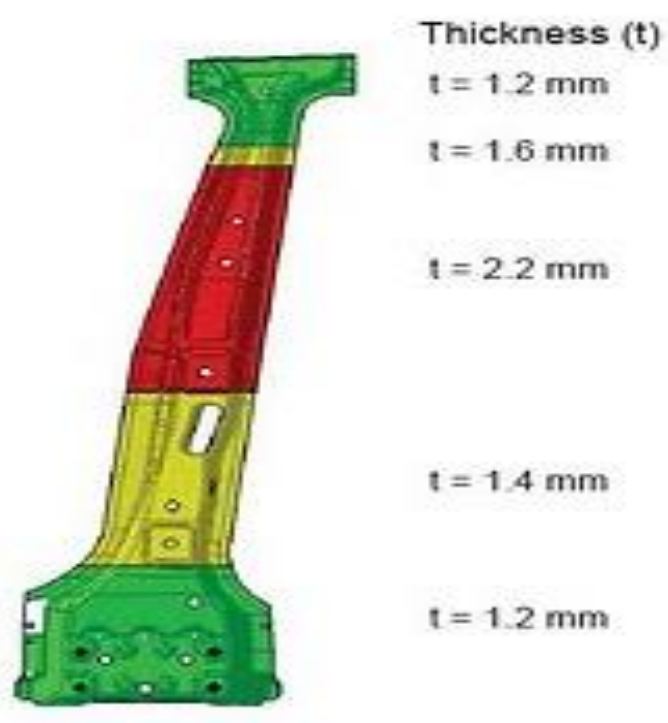

Figure 8. Example of a B-pillar design [13].

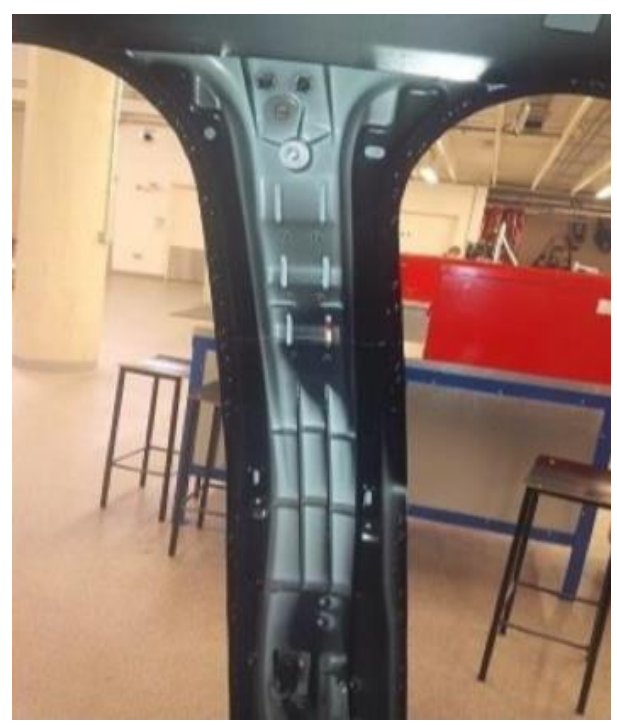

Figure 9. Audi B-pillar reinforcements in Coventry University workshop. 
For safety purposes, the B-Pillar should help protect drivers from risks in the occurrence of side impact scenarios. As such, safety regulations must be met. The FMVV 105 standard and EuroCAP regulations set out the criteria that a typical B-Pillar design must meet. The designs in Figure 7-9 use reinforcements such that the B-Pillar has varying thicknesses at various locations in the design. This was done to enhance the moment of inertia. The design is sometimes influenced by material properties and manufacturing processes. However, the cross-section of the structure has a role to play in both factors and oftentimes becomes the maximised or minimised function in B-Pillar design. This is done around the critical areas predetermined by the initial load case analysis.

\section{RESULTS AND DISCUSSION}

Table 3 represents the summary of the initial and final B-Pillar design analyses. Judging from the results obtained for mass, displacement, and von Mises stress, there is a distinctive difference in the values obtained from the original and final analyses, implying that the final (optimised B-Pillar) B-Pillar analysis can perform optimally in severe conditions.

Table 3. Summary of the initial and final B-pillar analyses.

\begin{tabular}{cccccc}
\hline \multicolumn{2}{c}{ Description } & \multicolumn{2}{c}{ Initial Analysis } & \multicolumn{2}{c}{ Final Analysis (Optimisation) } \\
\hline $\begin{array}{c}\text { Design } \\
\text { Name }\end{array}$ & B-Pillar & $\begin{array}{c}\text { Max von } \\
\text { Mises stress }\end{array}$ & $1646 \mathrm{MPa}$ & Mises stress & $673 \mathrm{MPa}$ \\
Load Case & $140 \mathrm{kN}$ & Displacement & $5.9 \mathrm{~mm}$ & Displacement & $2.39 \mathrm{~mm}$ \\
Analysis & Static & Initial Mass & $6 \mathrm{~kg}$ & Final Mass & $4.271 \mathrm{~kg}$ \\
\hline
\end{tabular}

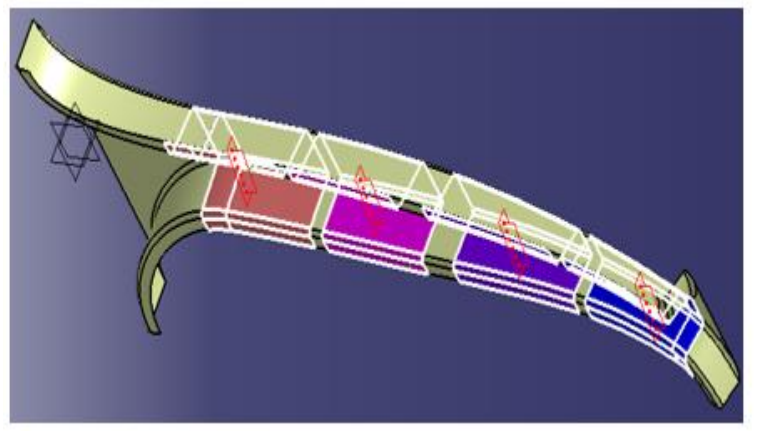

(a)

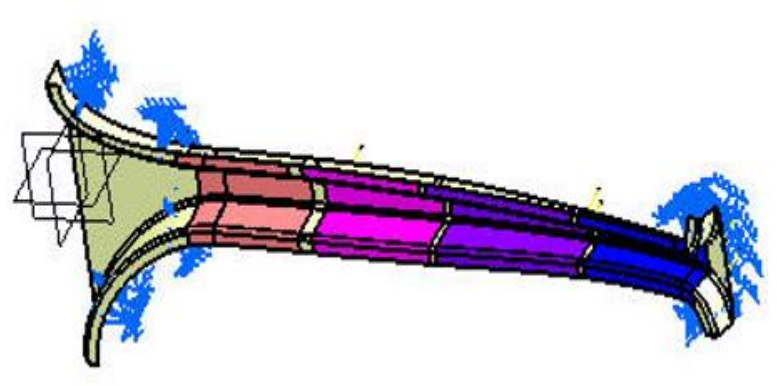

(b)

Figure 10. Final design of the B-Pillar with reinforcement and load case.

The outer B-Pillar surface remained the same throughout the design process. The reinforcement has similar physical properties to the outer surface of the B-pillar. The seam weld was used in joining the reinforcements with the outer surface. As shown earlier in Figures 6, the optimised B-Pillar design, however, had a mass of $4.271 \mathrm{~kg}$ with the reinforcements making up about $1.716 \mathrm{~kg}$ of the total design compared to the original $\mathrm{B}$ Pillar which had a mass of $6 \mathrm{~kg}$. The second moment of inertia of the final design was $1.929 \mathrm{e}-5 \mathrm{~m}^{4}$. In the first design, the use of spot welding made it difficult to produce the design. Some of the designs that failed in the process are shown in Appendix 1. After necessary adjustment, the design was done such that the factor of safety was within range, 
the structure remained within its elastic region throughout the test, and the maximum stress was around $673 \mathrm{MPa}$. The final B-pillar design with reinforcement is shown in Figure 10 (a), while the load case on final B-pillar design with reinforcement is shown in Figure 10(b). Appendix 1 represents some of the numerous difficult designs to be produced as a result of the application of spot welding and may not have the required strength to resist the forces acting on the B-pillar in crash scenarios. Appendix 2 shows the front view of the B-pillar design while Appendix 3 shows the isometric view of the B-pillar design with a scale of 1:5 each.

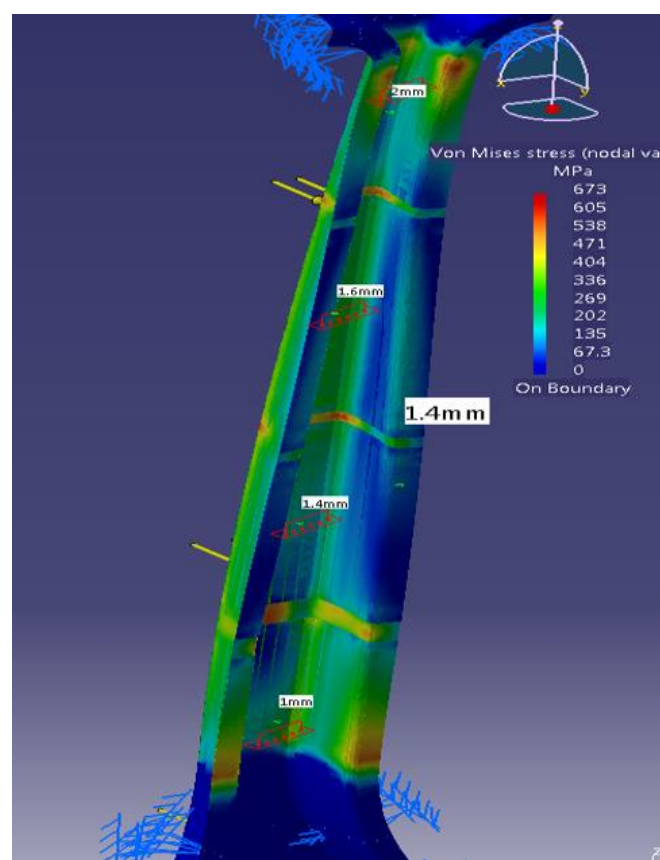

(a) von Mises stress

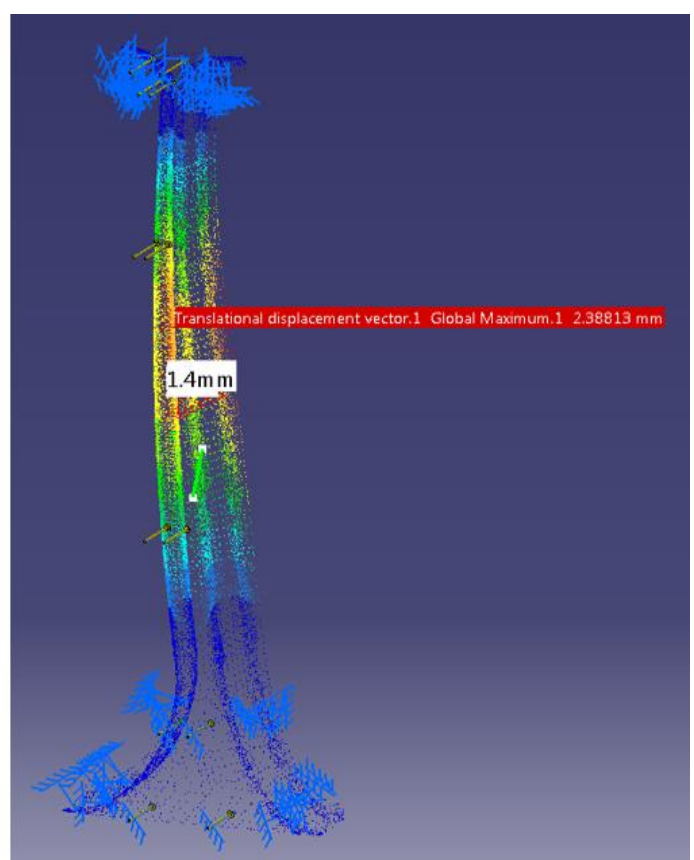

(b) Displacement

Figure 11. von Mises stress and maximum displacement of the final design.

The optimised design had four (4) reinforced layers replicating the original BPillar. The four reinforcements also have different thicknesses. The thickness depends on the nature of the stresses obtained from the initial analysis. Further modifications on the design can be obtained from running an optimisation procedure for the B-Pillar on any solver. As shown in Figure 11 (a), the maximum von Mises stress obtained for the optimised B-Pillar design was $673 \mathrm{MPa}$, quite lower than the maximum von Mises stress of $1646 \mathrm{MPa}$ obtained for the original B-Pillar analysis. As shown in Figure 11(b), the maximum displacement obtained from the optimised B-Pillar analysis was low $(2.39 \mathrm{~mm})$ compared to displacement value $(5.9 \mathrm{~mm})$ for the original B-Pillar. Applying a force of $140 \mathrm{kN}$, the B-Pillar produced resultant forces and moments along the $\mathrm{x}, \mathrm{y}$, and $\mathrm{z}$ directions as follows; $\mathrm{Fx}=-3.013 \mathrm{e}-007 \mathrm{~N}, \mathrm{Fy}=1.400 \mathrm{e}+005 \mathrm{~N}, \mathrm{Fz}=-1.555 \mathrm{e}-007 \mathrm{~N}, \mathrm{Mx}$ $=-7.646 \mathrm{e}+004 \mathrm{Nxm}, \mathrm{My}=-1.285 \mathrm{e}-006 \mathrm{Nxm}$ and $\mathrm{Mz}=-1.425 \mathrm{e}+003 \mathrm{Nxm}$. Ikpe et al. [31] proposed four (4) B-Pillar conceptual designs and the selected design had a maximum von Mises stress of $3.81 \mathrm{e}+003 \mathrm{MPa}$, the weight of $5.73 \mathrm{~kg}$, and maximum displacement of $13.8 \mathrm{~mm}$ which are comparably higher than the values obtained for similar parameters in this study. Using virtual test to optimise a B-Pillar by changing the B-Pillar material and thickness, Qiao and Shi [5] found out that increasing the material thickness was not an ideal approach but changing the material from steel to aluminium 
alloy greatly improved the crashworthiness of the B-Pillar. However, studies conducted by Parrish et al. [32] revealed that magnesium alloy can be optimised to improve crashworthiness characteristics with over $50 \%$ weight reduction in the redesign part. Contrarily, Lilehkoohi et al. [33] in their investigation proposed AISI1006 carbon steel for B-Pillar crash impact test but this may compromise the lightweight requirement due to its density which may contribute to fuel consumption rate of a given vehicle.

In all iterations, it was observed that the von Mises stress value was higher at the fillets. Since the given B-pillar design was Class 'A' surface, no changes were made to its geometry. However, modifying the filleted regions can possibly give better stress dissipation characteristics to the B-pillar assembly. Using lightweight materials can improve the vehicle fuel efficiency but could also compromise the strength of the B-pillar depending on the mechanical properties of the material and this could be reanalysed further.

\section{CONCLUSIONS}

Further developments can be carried out on the B-Pillar. However, this may require the use of optimisation technique rather than taking more iteration. The optimisation procedure will help ascertain points where reinforcements can be added as well as suggest places on the B-Pillar where materials can be removed. The whole process of iterating designs requires plenty of time. The optimisation technique will determine the load paths and this helps define the amount of material that should be at different locations within the design. The maximum stress on the B-Pillar was $673 \mathrm{MPa}$ and this was close to that required for the 1.25 factor of safety. One paramount limitation in the FEA solver was the ability to modify the meshes easily. This reduced the accuracy of the solutions obtained as they are highly dependent on the mesh quality. A possible error in the solution may also have resulted from accumulated approximations during the course of the numerical computations.

\section{ACKNOWLEDGEMENTS}

The authors of this manuscript would like to express their gratitude to Coventry University for providing the tools (used in achieving the objectives of this project-no. M10MAE) and guidance in terms of tutorial classes.

\section{REFERENCES}

[1] Dakin GJ, Arbelaez RA, Nolan JM, Zuby DS, Lund AK. Insurance institute for highway safety side impact crashworthiness evaluation program: Impact configuration and rationale. 18th International Technical Conference on the Enhanced Safety of Vehicles (CD-ROM). Washington: DC: National Highway Traffic Safety Administration.; 2003.

[2] Bodin H, Berglund D. B-pillar for a vehicle. US 8292354 B2; 2015.

[3] SIMULIA. Prediction of b-pillar failure in automobile bodies. Retrieved from http://www.3ds.Com/fileadmin/products/simulia/pdf/tech-briefs/auto-predictionof-b-pillar-failure-automobile-bodies-08.Pdf. 24 November, 2015.

[4] Borst D, Crisfield R, Remmers M, Verhoosel C. Nonlinear finite element analysis of solids and structures: John Wiley \& Sons; 2012. 
[5] Qiao WG, Shi WY. Simulation and optimization of b-pillar crashworthiness based on virtual test. Applied Mechanics and Materials: Trans Tech Publ; 2014. p. 5056: $380-3$.

[6] Lilehkoohi A, Faieza A, Sahari B, Nuraini A, Halali M. Crashworthiness determination of side doors and $\mathrm{b}$ pillar of a vehicle subjected to pole side impact. Applied Mechanics and Materials. 2014;663:552-6.

[7] Kamal M, Rahman MM. Finite element-based fatigue behaviour of springs in automobile suspension. International Journal of Automotive and Mechanical Engineering. 2014;10:1910-9.

[8] Ariffin AH, Solah MS, Azhar H, Isa M, Hafzi M, Rahman MK, et al. Development of mobile deformable barrier for side impact crashworthiness evaluation in asean new car assessment programme (ASEAN NCAP). In Applied Mechanics and Materials. 2014;663:562-6.

[9] Ahmad Z, Nagel G, Thambiratnam D. Inclusion of tapered tubes in enhancing the crash performance of automotive frontal structures. Key Engineering Materials: Trans Tech Publ; 2013. p. 1-6.

[10] Naghipour M, Nemati M, Doostdar H. Experimental study and modeling of reinforced concrete beams strengthened by post-tensioned external reinforcing bars. International Journal of Engineering. 2010;23:127-44.

[11] Huetter J. 2016 honda hr-v is ultra-popular -and 27 percent ultra-high-strength steel. Retrievd from http://www.Repairerdrivennews.Com/2015/06/24/2016honda-hr-v-is-ultra-popular-and-27-percent-ultra-high-strength-steel/.

[12] EURONCAP. Car to car side impact euro ncap - for safer car crash test safety rating. Retrieved from http://www.Euroncap.Com/content-web-page/106f41f7d486-46bf-bfbc-80fb4c79f679/car-to-car-side-impact.Aspx.

[13] Carney D. The new crash test that will change your next car. Retried from http://www.Popularmechanics.Com/cars/a8070/the-new-crash-test-that-willchang-your-next-car-11980742/. 14 July, 2015.

[14] Njuguna J. The application of energy-absorbing structures on side impact protection systems. International Journal of Computer Applications in Technology. 2011;40:280-7.

[15] Jawi ZM, Isa MHM, Mohamed N, Awang A, Osman MR. A systemic analysis of the usage of safety items among malaysian private vehicle users. Journal of Mechanical Engineering and Sciences. 2016;10:2262-74.

[16] Reddy S. Modeling and analysis of a composite b-pillar for side-impact protection of occupants in a sedan: Wichita State Uniersity, USA.; 2003.

[17] Rahman N, Abdullah S, Abdullah M, Zamri W, Omar M, Sajuri Z. Energy absorption capability and deformation of laminated panels for armoured vehicle materials. International Journal of Automotive and Mechanical Engineering. 2016;13:3657-68.

[18] Analysis FRFE. In a. N. Gent, engineering with rubber: How to design rubber components. Munich: Hanser Publishers; 2011.

[19] Reddy JN. An introduction to the finite element method: McGraw-Hill New York; 2005.

[20] Kamal M, Rahman MM. An integrated approach for fatigue life estimation based on continuum mechanics theory and genetic algorithm. International Journal of Automotive and Mechanical Engineering. 2015;11:2756-70. 
[21] Rahman MM, Ariffin AK, Rejab MRM, Kadirgama K, Noor MM. Multiaxial fatigue behavior of cylinder head for a free piston linear engine. Journal of Applied Sciences. 2009;9:2725-34.

[22] Blackwell W. Retrieved from http://www.Colorado.Edu/engineering/cas/courses.D/ifem.D/. 4 March, 2013.

[23] Kazerouni S, Saidi A, Mohammadi M. Buckling analysis of thin functionally graded rectangulare plates with two opposite edges simply supported. International Journal of Engineering Transactions B: Applications. 2010;23:17992.

[24] NAFEMS. The importance of mesh convergence- Part 1 Engineering analysis and simulation-FEA, finite element analysis, CFD, computational fluid dynamics and simulation.

Retrieved from http://nafems.Org/join/resources/knowledgebase/001/.Htm. 6 September, 2015.

[25] Frederick A, Dominic J. Strength and stiffness of engineering systems. Springer, New York Google Scholar; 2009.

[26] Hicks TG. Handbook of Civil Engineering Calculations; 2007.

[27] Ahmad Z, Othman M. Energy absorption performance of a rain forest vehicle under frontal impact. Journal of Mechanical Engineering and Sciences. 2014;6:807-17.

[28] Elkady M, Elmarakbi A, MacIntyre J. Integration of vehicle dynamics control systems with an extendable bumper for collision mitigation. International Journal of Automotive and Mechanical Engineering. 2015;12:2893-913.

[29] Budynas RG, Nisbett JK. Shigley's mechanical engineering design: McGraw-Hill New York; 2008.

[30] Lombardi M. Body b-pillar. Retrieved from http://www.Primapower.Com/media/uploads/editorialtext/docs/85bec587ceed 83 1 feff1e11f1f82c456.Pdf. 15 July, 2008.

[31] Ikpe AE, Orhorhoro EK, Gobir A. Design and reinforcement of a b-pillar for occupants safety in conventional vehicle applications. International Journal of Mathematical, Engineering and Management Science. 2017;2:37-52.

[32] Parrish A, Rais-Rohani M, Najafi A. Crashworthiness optimization of vehicle structures with magnesium alloy parts. International Journal of Crashworthiness. 2012; 17:259-81.

[33] Lilehkoohi A, Faieza A, Sahari B, Nuraini A, Halali M. Effect of material on crashworthiness for side doors and $\mathrm{b}$ pillar subjected to euro ncap side impact crash test. Journal of Advanced Letters. 2013;19:359-62. 


\section{APPENDICES}

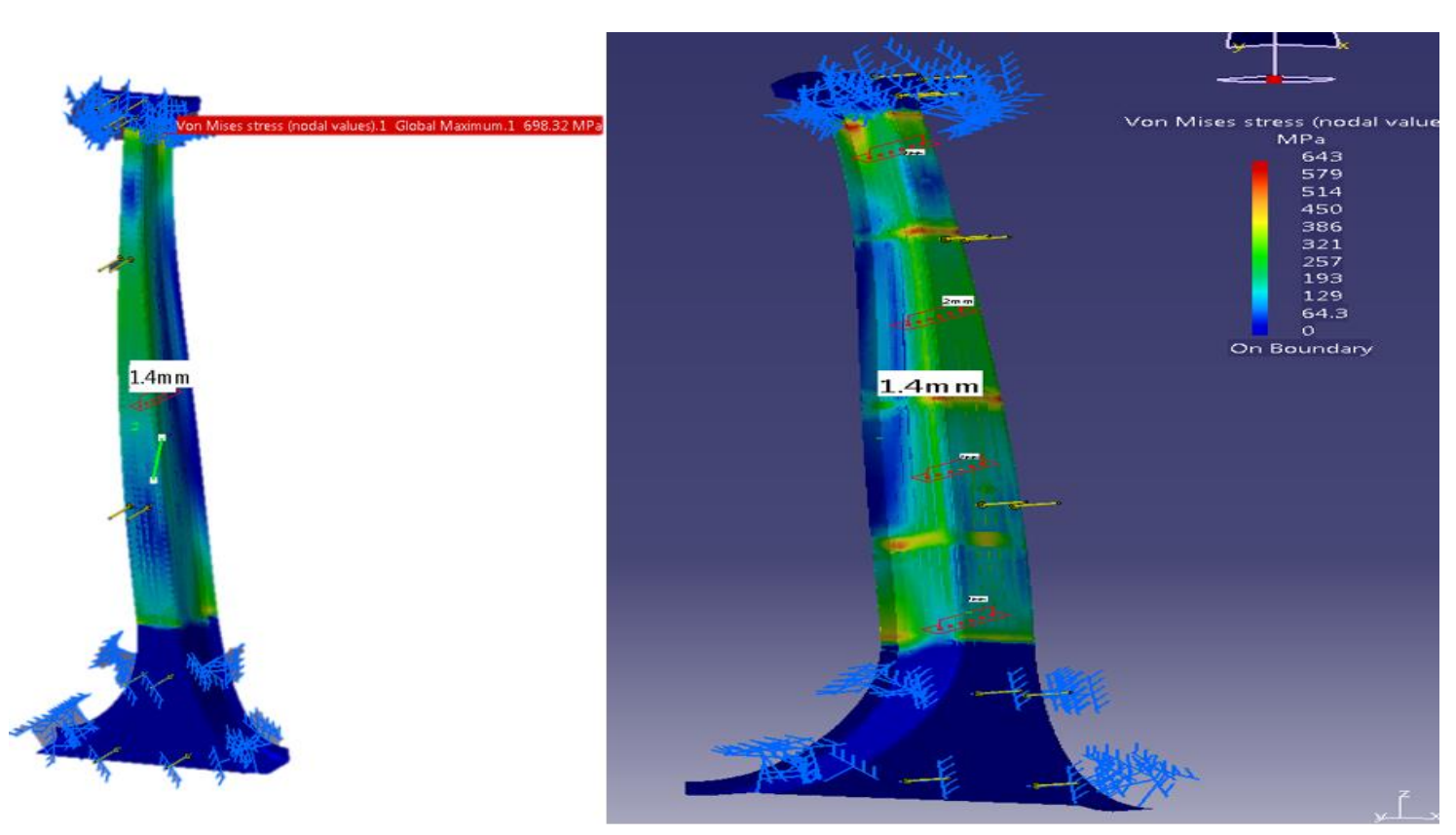

Appendix 1. One of the attempts achieved while trying to reduce the von-Mises stress on the B-pillar.

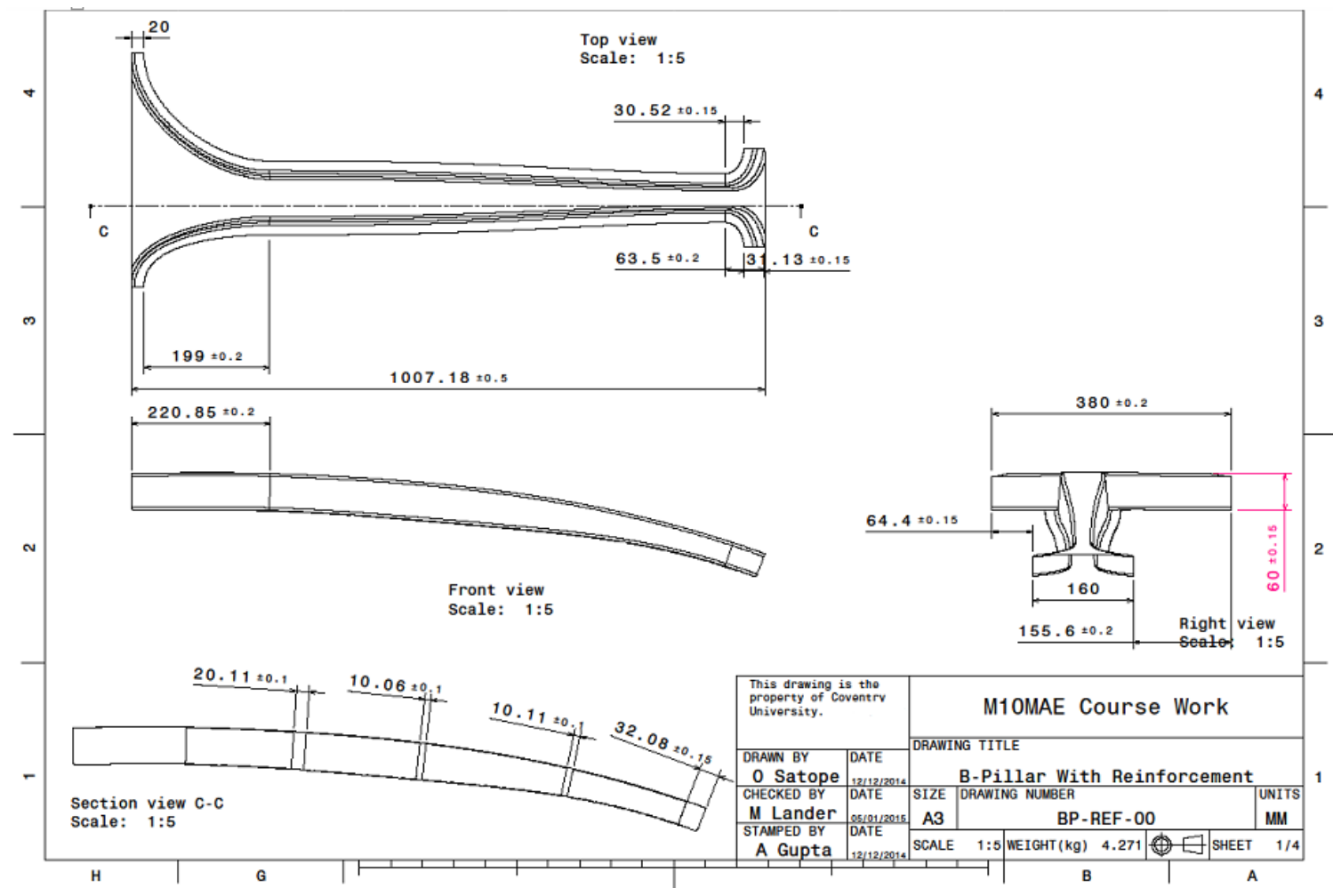

Appendix 2. Front view of the B-pillar design 


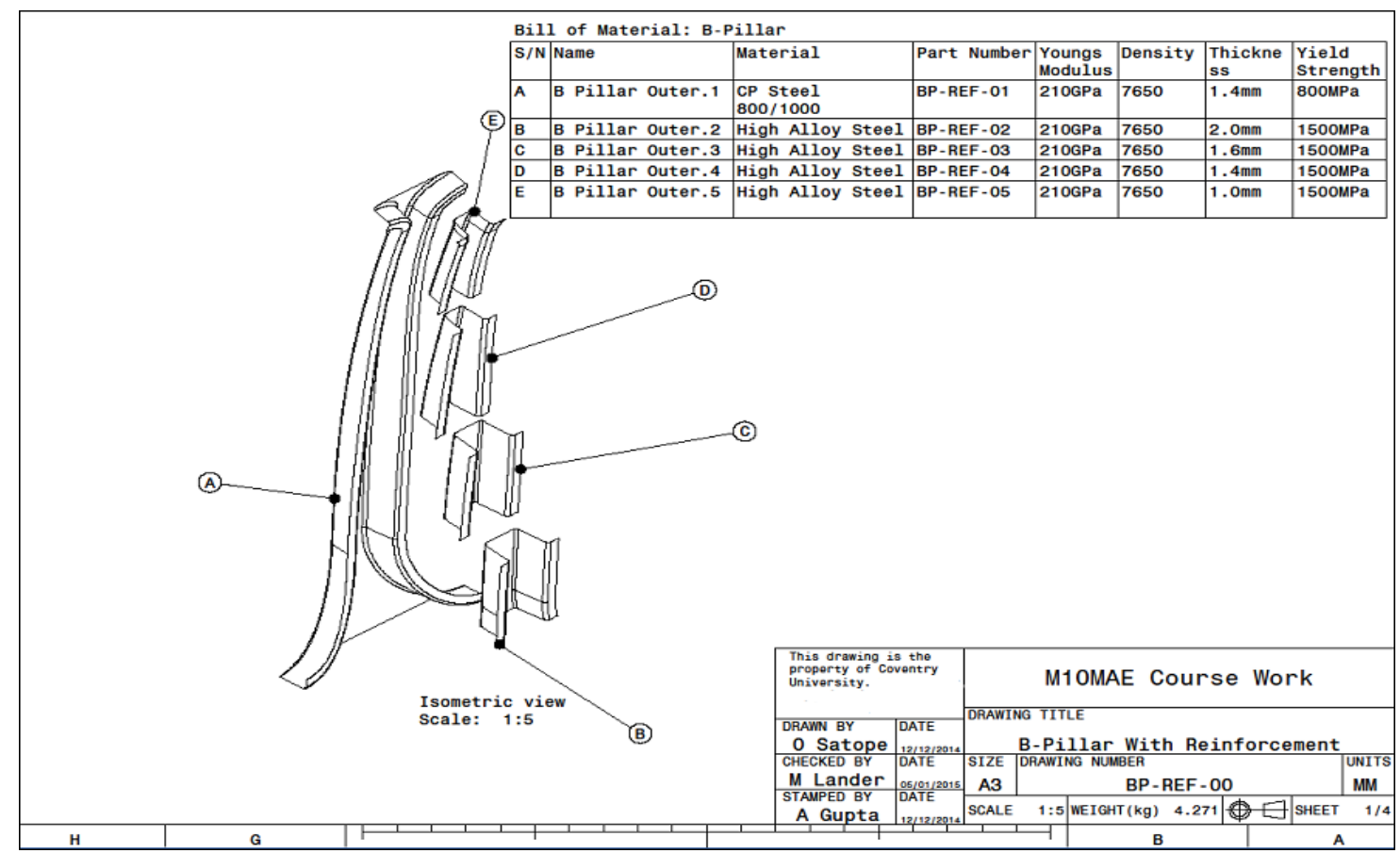

Appendix 3. Isometric view of the B-pillar design 